Article

\title{
Investigation of Electrochemically Deposited and Chemically Reduced Platinum Nanostructured Thin Films as Counter Electrodes in Dye-Sensitized Solar Cells
}

\author{
Chih-Hung Tsai *, Yu-Chen Hsiao and Ping-Yuan Chuang \\ Department of Opto-Electronic Engineering, National Dong Hwa University, Hualien 97401, Taiwan; \\ 610025012@gms.ndhu.edu.tw (Y.-C.H.); 610125012@gms.ndhu.edu.tw (P.-Y.C.) \\ * Correspondence: cht@mail.ndhu.edu.tw; Tel.: +886-3-863-4199
}

Received: 22 November 2017; Accepted: 31 January 2018; Published: 1 February 2018

\begin{abstract}
In this paper, we demonstrated that platinum (Pt) counter electrodes (CEs) fabricated using electrochemical deposition and chemical reduction can replace conventional high-temperature thermally decomposed Pt electrodes. In this study, Pt electrodes were fabricated using thermal decomposition, electrochemical deposition, and chemical reduction, and the influence of the different Pt counter electrodes on the efficiency of the dye-sensitized solar cells (DSSCs) was analyzed. The properties of the various Pt CEs were analyzed using scanning electron microscopy (SEM), surface area analysis, X-ray diffraction (XRD), electrochemical impedance spectroscopy (EIS), and cyclic voltammetry $(\mathrm{CV})$. DSSCs with various Pt CEs were characterized using current density-voltage $(\mathrm{J}-\mathrm{V})$, incident photo-current conversion efficiency (IPCE), and EIS measurements. The results show that the power conversion efficiencies of these three types of DSSC devices were between $7.43 \%$ and $7.72 \%$. The DSSCs based on the Pt electrode fabricated through electrochemical deposition exhibited the optimal power conversion efficiency. Because the processes of electrochemical deposition and chemical reduction do not require high-temperature sintering, these two methods are suitable for the fabrication of Pt on flexible plastic substrates.
\end{abstract}

Keywords: dye-sensitized solar cell; counter electrode; platinum; thermal decomposition; electrochemical deposition; chemical reduction

\section{Introduction}

In the twenty-first century, humans are facing energy shortage and environmental pollution problems. The use of fossil fuels to generate energy has resulted in global warming, abnormal climates, and environmental pollution. Thus, researchers have actively studied and developed new alternative energy or renewable energy technologies. Solar energy is the most advantageous renewable energy because it is inexhaustible, is not influenced by geographical location, and does not cause environmental pollution. In 1991, a Swiss research team led by Grätzel developed a high-efficiency and low-cost dye-sensitized solar cell (DSSC), prompting a trend of DSSC-related research [1]. Grätzel's team fabricated a porous thin-film electrode using $\mathrm{TiO}_{2}$ nanoparticles that have a large surface area and used a Ru-complex dye adsorbed on the $\mathrm{TiO}_{2}$ electrode. In addition, the $\mathrm{I}^{-} / \mathrm{I}_{3}{ }^{-}$redox couple was adopted as the electrolyte, and a counter electrode made of a conductive glass substrate with platinum $(\mathrm{Pt})$ was used [2]. Because the dye has ideal spectral characteristics and the $\mathrm{TiO}_{2}$ nanoparticles have a large surface area that can considerably increase the amount of dye adsorption, incident light can be fully utilized to excite the dye molecules to produce photoelectrons. Therefore, the photoelectric conversion efficiency of DSSCs was increased to $7.9 \%$. This research outcome immediately attracted 
great attention and motivated researchers to actively conduct relevant studies. DSSCs have the advantages of high efficiency, low cost, and simple fabrication and therefore have the potential to compete with traditional silicon-based solar cells [3-12].

The DSSC device structure comprises a transparent conductive substrate, a $\mathrm{TiO}_{2}$ nanoparticle thin film, a dye, an electrolyte, and a counter electrode [13]. The counter electrode is a crucial part of the DSSC and provides electrons for the redox couple in the electrolyte [14-22]. Therefore, the redox couple can transmit electrons to the dye, causing the dye to change from an excited state to the ground state, which facilitates dye regeneration. Conventionally, the fabrication method for a DSSC Pt counter electrode involves adopting the sputtering method to fabricate Pt thin films on conductive glass. Alternatively, chloroplatinic acid $\left(\mathrm{H}_{2} \mathrm{PtCl}_{6}\right)$ is used as a $\mathrm{Pt}$ precursor and is sintered at $450{ }^{\circ} \mathrm{C}$ to facilitate thermal decomposition, forming Pt nanoparticles on the surface of the conductive glass [23-26]. Generally, using the sputtering method to fabricate Pt requires a high-vacuum sputtering system $[27,28]$. Conversely, the method of thermal decomposition requires high-temperature sintering and is therefore unsuitable for the fabrication of $\mathrm{Pt}$ on flexible plastic substrates.

This study employed the methods of electrochemical deposition and chemical reduction to fabricate Pt counter electrodes for DSSCs and then investigated the influence of the fabricated Pt counter electrodes on the efficiency of DSSC devices. Electrochemical deposition is an approach for depositing metals [29]. Specifically, the metal to be deposited is placed at the cathode, and the electrolyte comprises metal ions or complex ions. Under the current effect, the metal undergoes a reduction reaction and deposits on the electrode surface. Factors influencing the electrochemical deposition include the polarizability of the cathode, current intensity, electrolyte composition, conductivity, temperature, and $\mathrm{pH}$ level. The method of electrochemical deposition features the following advantages: (a) the method does not require high-temperature or high-vacuum equipment; that is, the required equipment is simple; (b) the fabricated thin film provides uniform coverage; (c) the fabrication process is simple and easy to control; (d) the shape of the substrate is not highly restricted, and provides a large area for film formation; and (e) film formation occurs rapidly. This method can be widely applied to thin films of metals, oxides, organic materials, carbides, fluorescent materials, ceramic materials, nitrides, and polymers. In addition, it has been reported that $\mathrm{Pt}$ can be prepared by chemical reduction [30]. The chemical reduction reaction is used to reduce the platinum precursor $\mathrm{H}_{2} \mathrm{PtCl}_{6}$ to platinum using sodium borohydride $\left(\mathrm{NaBH}_{4}\right)$. Because electrochemical deposition and chemical reduction do not require high-temperature sintering for fabricating the $\mathrm{Pt}$ counter electrode, $\mathrm{Pt}$ can be deposited on flexible plastic substrates that cannot endure high temperatures.

\section{Experimental Methods}

\subsection{Using Electrochemical Deposition and Chemical Reduction to Fabricate Pt Counter Electrodes}

Fluorine-doped tin oxide (FTO) transparent conductive glass, which measured $2.5 \mathrm{~cm} \times 2.0 \mathrm{~cm}$ in size, was prepared. Two holes were drilled in the FTO glass for infusing the electrolyte. The FTO glass substrate was placed into acetone and washed for $10 \mathrm{~min}$ using an ultrasonic cleanser, followed by the successive addition of deionized water, ethanol, and deionized water for $10 \mathrm{~min}$. Finally, nitrogen was used to dry the surface of the FTO glass. This study employed a three-electrode electrochemical deposition apparatus that comprised a working electrode, counter electrode, and reference electrode, as shown in Figure 1a. In this study, a gold $(\mathrm{Au})$ electrode was adopted as the working electrode and placed in contact with the FTO substrate for the deposition of the metal. Pt was used as the counter electrode, and the reference electrode was made of silver/silver chloride ( $\mathrm{Ag} / \mathrm{AgCl})$. The three electrodes were separately immersed in an electrolyte. The electrolyte solution contained $0.5 \mathrm{M}$ sulfuric acid $\left(\mathrm{H}_{2} \mathrm{SO}_{4}\right)$ and $5 \mathrm{mM} \mathrm{K}_{2} \mathrm{PtCl}_{6}$. An electrochemical analyzer (6116D, $\mathrm{CH}$ Instruments, Inc., Austin, TX, USA) was employed to apply $0.2 \mathrm{~V}$ to the electrolytic solution, and the $\mathrm{Pt}$ thin film was deposited on the FTO substrate at $25^{\circ} \mathrm{C}$ for $10 \mathrm{~min}$. After electrochemical deposition, the excess electrolyte on the substrate was washed off using deionized water, and the substrate surface was dried using nitrogen. 
(a)

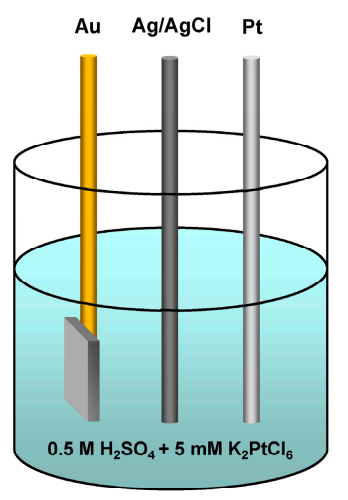

(b)

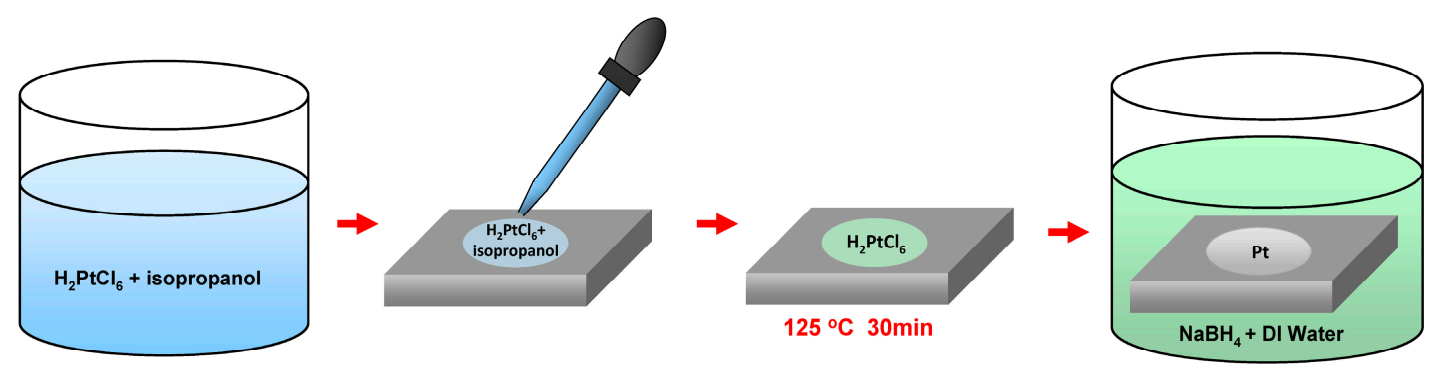

Figure 1. (a) Three-electrode electrochemical deposition apparatus used for preparation Pt counter electrode and (b) the preparation process of the Pt counter electrode by chemical reduction.

The preparation process of the Pt counter electrode by chemical reduction is shown in Figure $1 \mathrm{~b}$. First, a chloroplatinic acid $\left(\mathrm{H}_{2} \mathrm{PtCl}_{6}\right)$ solution $(5 \mathrm{mM})$ was prepared in isopropanol. The chloroplatinic acid solution was dropped on the conductive FTO substrate and sintered at $125^{\circ} \mathrm{C}$ in air for $30 \mathrm{~min}$. Then, $\mathrm{NaBH}_{4}(20 \mathrm{mM})$ was added to $10 \mathrm{~mL}$ of deionized water. The dried substrate was immersed in the $\mathrm{NaBH}_{4}$ solution at $40{ }^{\circ} \mathrm{C}$ for $2 \mathrm{~h}$, and the substrate was finally removed and rinsed with deionized water to complete the preparation of the platinum counter electrode. For comparison, a traditional $\mathrm{Pt}$ counter electrode fabricated using thermal decomposition was also prepared by applying a platinum paste onto an FTO substrate using a doctor blade-coating method and sintering at $400{ }^{\circ} \mathrm{C}$ for $30 \mathrm{~min}$.

\subsection{DSSC Device Fabrication}

The method for fabricating the counter electrode of DSSCs has been described in Section 2.1, and the method for fabricating the working electrode of the DSSC is as follows: the FTO conductive glass was first cleaned as the platinized FTO substrate, and then $3 \mathrm{M}$ tape (50- $\mu \mathrm{m}$-thick) containing a 4-mm diameter hole was attached. The area of the hole was $0.126 \mathrm{~cm}^{2}$, which was used as the active area for the device. Next, a paste of $25 \mathrm{~nm} \mathrm{TiO}{ }_{2}$ nanoparticles was coated on the area using the blade-coating method and was heated at $150{ }^{\circ} \mathrm{C}$ for $10 \mathrm{~min}$. Afterwards, the conductive glass was left to cool to room temperature. The steps for the $\mathrm{TiO}_{2}$ coating were repeated to obtain a $\mathrm{TiO}_{2}$ working electrode with a thickness of $12 \mu \mathrm{m}$. The blade-coating method was employed to coat a layer of $\mathrm{TiO}_{2}$ paste with a particle size of $200 \mathrm{~nm}$ on top of the $\mathrm{TiO}_{2}$ working electrode to serve as the scattering layer. Subsequently, the test piece was put into the furnace and sintered at $500{ }^{\circ} \mathrm{C}$ for $30 \mathrm{~min}$. After cooling to room temperature, the $\mathrm{TiO}_{2}$ working electrode was immersed in a dye solution for $24 \mathrm{~h}$. For the dye solution, $0.5 \mathrm{mM}$ N719 dye was used with $0.5 \mathrm{mM}$ chenodeoxycholic acid (CDCA) as the co-adsorbent, and the solvent was formed by mixing acetonitrile with tert-butyl alcohol at a volume ratio of 1:1. Subsequently, an encapsulating film, with a thickness of $60 \mu \mathrm{m}$, was cut to the size of $2.5 \mathrm{~cm} \times 2.5 \mathrm{~cm}$ with an area of $0.8 \mathrm{~cm} \times 0.8 \mathrm{~cm}$ cut out from its center. The working and counter electrodes were assembled using the encapsulating film with a pressure of $3 \mathrm{~kg} / \mathrm{cm}^{2}$ at a temperature 
of $130^{\circ} \mathrm{C}$. The pressure was applied for $3 \mathrm{~min}$ to ensure that the upper and lower electrodes were closed. After the assembled device was left to cool, $5 \mu \mathrm{L}$ of the electrolyte was infused into the device using a micropipette. The electrolytic solution comprised $0.6 \mathrm{M}$ 1-butyl-3-methylimidazolium iodide (BMII), 0.05 M LiI, 0.03 $\mathrm{M} \mathrm{I}_{2}$, 0.5 M 4-tert-butyloyridine, $0.1 \mathrm{M}$ guanidine thiocyanate, and acetonitrile and valeronitrile with a volume ratio of $5: 1$. The $0.8 \mathrm{~cm} \times 0.8 \mathrm{~cm}$ of the encapsulating film and a glass plate were used to seal the hole of the counter electrode at a temperature of $130{ }^{\circ} \mathrm{C}$ under a pressure of $3 \mathrm{~kg} / \mathrm{cm}^{2}$ to prevent the electrolytic solution from leaking and volatilizing. Finally, the surface of the solar cell was wiped clean using alcohol to finish the fabrication of the DSSC device.

\subsection{Characteristic Analyses of the Counter Electrodes and the DSSC Devices}

This study conducted the following analyses on the Pt counter electrode: the surface morphology and crystal structure of the Pt electrode were analyzed and observed using a scanning electron microscope (SEM) (JSM-7000F, JEOL, Ltd., Tokyo, Japan) and X-ray diffractometer (XRD) (D/Max-2500V, Rigaku Corp., Tokyo, Japan) with a $\mathrm{Cu}-\mathrm{K} \alpha$ radiation source and Bragg-Brentano geometry, respectively, and the catalytic activity of the electrode was measured by employing cyclic voltammetry (CV) (6116D, CH Instruments, Inc., Austin, TX, USA). The Brunauer-Emmett-Teller (BET) specific surface area of the Pt electrode was determined using a surface area analyzer (ASAP 2020, Micromeritics Instrument Corp., Norcross, GA, USA). The electrochemical impedance spectroscopy (EIS) measurements of the simple symmetric devices (Pt-electrolyte-Pt) were performed using an impedance analyzer (6116D, CH Instruments, Inc., Austin, TX, USA). Subsequently, this study used different $\mathrm{Pt}$ counter electrodes to fabricate DSSC devices and investigated the influence of the different types of counter electrodes on the characteristics of the DSSC devices. Finally, the device characteristics of the DSSCs were comprehensively analyzed using the current density-voltage (J-V), incident photo-current conversion efficiency (IPCE), and EIS measurement. The complete details of the measurements are described in a report of our previous work [31].

\section{Results and Discussion}

\subsection{Characteristic Analysis of the Pt Counter Electrode}

Figure 2 shows the SEM images of the Pt electrode fabricated through thermal decomposition, electrochemical deposition, and chemical reduction. The particle size of the Pt electrode fabricated using thermal decomposition was approximately $60 \mathrm{~nm}$ to $80 \mathrm{~nm}$, and the Pt nanoparticles were distributed on the substrate evenly. The Pt electrode fabricated using the electrochemical deposition had a globular/agglomerated structure; the size of the globular/agglomerated structure ranged from $200 \mathrm{~nm}$ to $800 \mathrm{~nm}$; and textured Pt nanostructures were observed on the surface of the globular/agglomerated structures. In addition, the Pt electrode fabricated using the electrochemical deposition showed a lower distribution density of Pt globular/agglomerated structure on FTO substrate. The Pt electrode prepared by chemical reduction had a coral-like structure; the size of the coral-like structure was approximately $600 \mathrm{~nm}$ to $1200 \mathrm{~nm}$; and the coral-like structure was composed of spherical Pt with a diameter of $100 \mathrm{~nm}$. The BET specific surface areas of the three Pt electrodes were determined using a surface area analyzer, and the surface areas of the Pt electrode fabricated through thermal decomposition, electrochemical deposition, and chemical reduction were $21.6 \mathrm{~m}^{2} / \mathrm{g}, 31.4 \mathrm{~m}^{2} / \mathrm{g}$, and $23.5 \mathrm{~m}^{2} / \mathrm{g}$, respectively. Among the three Pt electrodes, the Pt electrode fabricated through electrochemical deposition exhibited the largest surface area. This is attributed to the agglomeration of the textured Pt nanostructures on the surface of the globular/agglomerated structures.

Subsequently, this study adopted XRD to analyze the Pt electrode fabricated through thermal decomposition, electrochemical deposition, and chemical reduction, respectively. The result of the XRD measurement is displayed in Figure 3. The XRD signal peaks for FTO conductive substrates $\left(\mathrm{SnO}_{2}: \mathrm{F}\right)$ were found at $26.5^{\circ}, 33.8^{\circ}, 37.9^{\circ}, 51.7^{\circ}, 54.8^{\circ}, 61.7^{\circ}$, and $78.4^{\circ}$. The peak values of the XRD signals corresponding to $\mathrm{Pt}$ were $39.7^{\circ}, 46.4^{\circ}$, and $67.5^{\circ}$, and the corresponding lattice planes were 
$(1,1,1),(2,0,0)$, and $(2,2,0)$. Moreover, the signal peaks for the Pt electrode fabricated through electrochemical deposition were significantly higher than those for the Pt electrodes fabricated through thermal decomposition and chemical reduction, indicating that the Pt electrode fabricated using electrochemical deposition had a relatively satisfactory crystallinity. The surface morphology, structure size, distribution density, and crystallinity of Pt electrode would affect the conductivity and catalytic activities of the Pt CE.

(a)

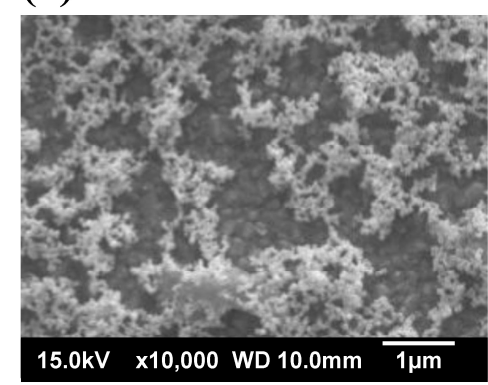

(b)

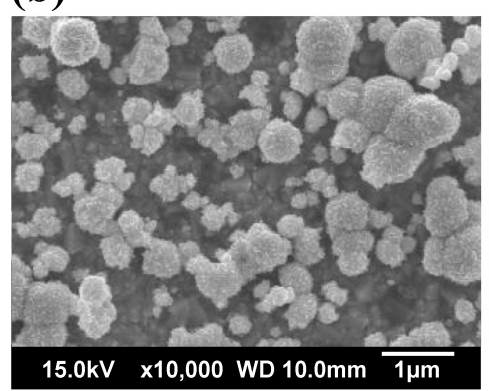

(c)

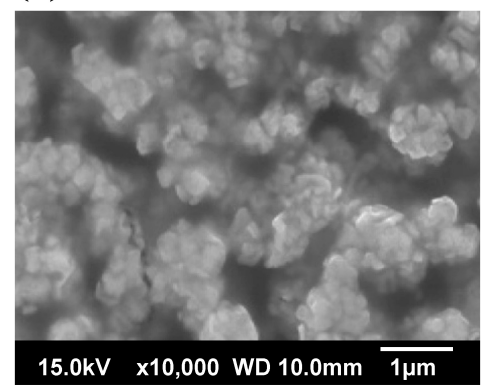

Figure 2. SEM images of (a) the Pt electrode fabricated through thermal decomposition; (b) the Pt electrode fabricated through electrochemical deposition; and (c) the Pt electrode fabricated through chemical reduction.

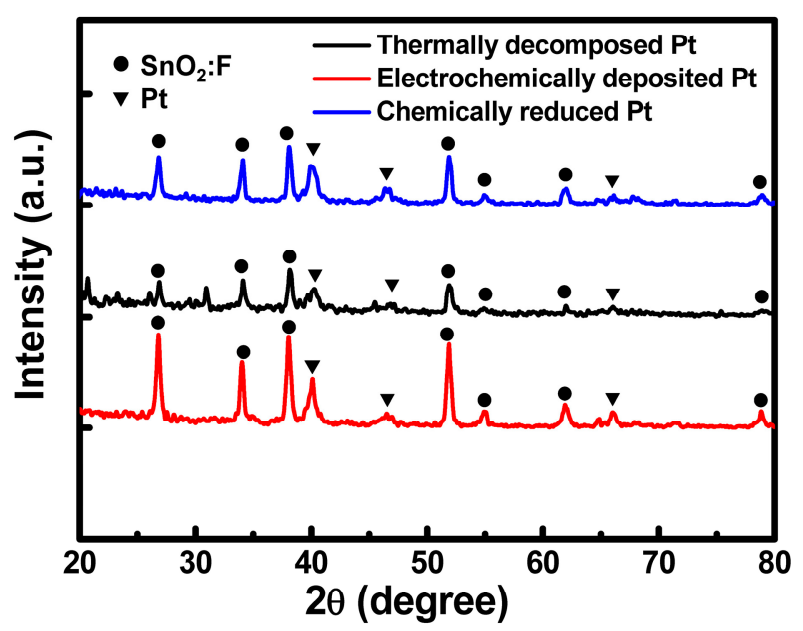

Figure 3. XRD spectra of various Pt CEs.

A simple symmetric device was fabricated by assembling two identical Pt electrodes with the electrolyte; this device was subjected to EIS analysis. In Figure 4, the left semicircle represents the interface impedance between the Pt CEs and electrolyte, and the right semicircle represents the diffusion resistance of the electrolyte. The experimental results showed that the interface impedance of the Pt electrode fabricated using electrochemical deposition was larger than that of the Pt electrodes fabricated through thermal decomposition and chemical reduction, indicating a larger resistance of the Pt electrode fabricated using electrochemical deposition. The possible reasons for this result were the agglomeration of $\mathrm{Pt}$ nanostructures in the electrode and the lower distribution density of the $\mathrm{Pt}$ globular/agglomerated structure on the FTO substrate, which resulted in a larger electrical resistance. In addition, the coral-like Pt electrode prepared by chemical reduction exhibited lower charge transfer impedance between the Pt CEs and electrolyte. 


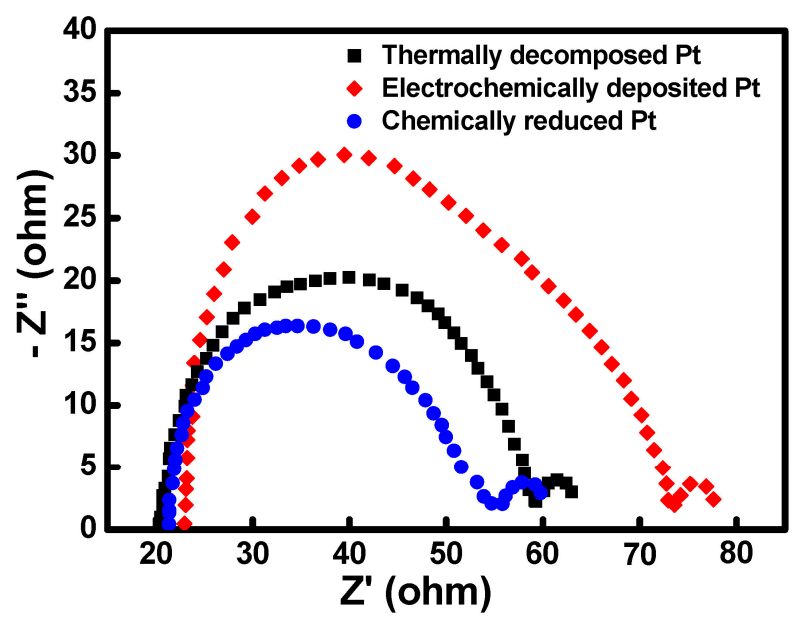

Figure 4. The EIS analytic results of simple symmetric devices (Pt-electrolyte-Pt).

This study further adopted CV to measure the three types of Pt electrodes to investigate their electrochemical catalytic property, as shown in Figure 5. The electrochemical catalytic property of the Pt electrodes can be determined by the magnitude of the reduction current density in the $\mathrm{CV}$ diagram; the $\mathrm{CV}$ result showed that the reduction current density for the Pt electrode fabricated using electrochemical deposition was larger than that of the Pt electrodes fabricated through thermal decomposition and chemical reduction reaction. The experimental results revealed that although agglomeration of $\mathrm{Pt}$ nanostructures in the electrochemically deposited Pt electrode exhibited a larger electrical resistance, it also exhibited an increased surface area, enhancing the reduction current density in the CV diagram. Overall, the Pt electrode fabricated through electrochemical deposition exhibited optimal electrochemical catalytic capabilities. The high electrocatalytic activity of the Pt electrode fabricated through electrochemical deposition is ascribed to its large surface area and good crystalline nature, as exhibited by SEM, BET, and XRD results.

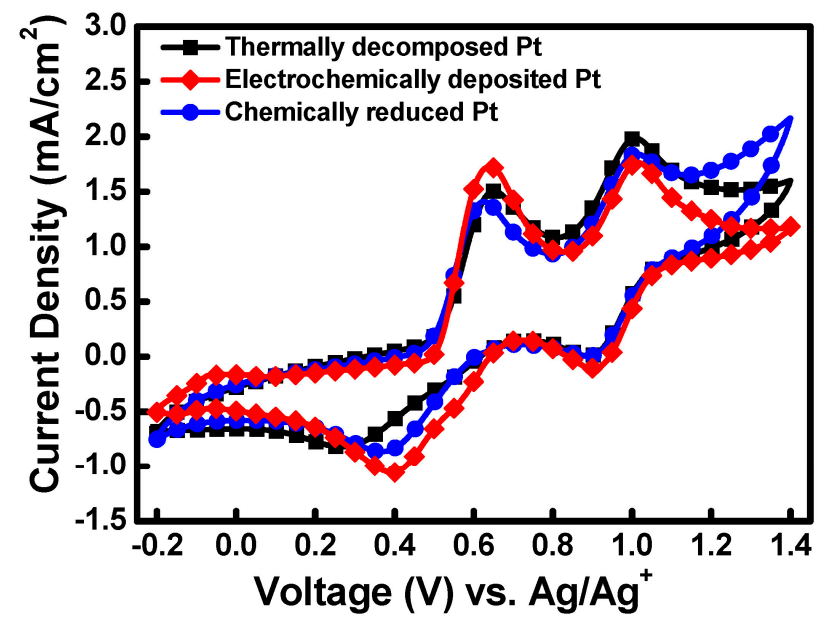

Figure 5. Cyclic voltammograms of various Pt CEs.

\subsection{Characteristic Analysis of the DSSC Devices}

In addition, this study used different Pt counter electrodes to fabricate DSSC devices and investigated their influence on the characteristics of the DSSC devices. Figure 6 shows the J-V measurement results of the DSSC devices, and the obtained parameters are listed in Table 1 . The reproducibility of the device performances based on various CEs was investigated. For each CE, five identical DSSC devices were fabricated and analyzed. The values shown in Tale 1 are averaged 
values and stand deviations of five devices made under identical conditions. According to the experimental result, the short-circuit current density $\left(J_{\mathrm{SC}}\right)$, open-circuit voltage $\left(V_{\mathrm{OC}}\right)$, fill factor $(F F)$, and efficiency of the DSSC using the Pt counter electrode fabricated through thermal decomposition were $16.01 \mathrm{~mA} / \mathrm{cm}^{2}, 0.76 \mathrm{~V}, 0.63$, and $7.66 \%$, respectively. The $J_{\mathrm{SC}}, V_{\mathrm{OC}}, F F$, and efficiency of the DSSC using the Pt counter electrode fabricated through electrochemical deposition were $17.16 \mathrm{~mA} / \mathrm{cm}^{2}$, $0.75 \mathrm{~V}, 0.60$, and $7.72 \%$, respectively. The $J_{\mathrm{SC}}, V_{\mathrm{OC}}, F F$, and efficiency of the DSSC using the Pt counter electrode fabricated through chemical reduction were $16.34 \mathrm{~mA} / \mathrm{cm}^{2}, 0.70 \mathrm{~V}, 0.65$, and $7.43 \%$, respectively. The results showed that among the three Pt electrodes, DSSCs based on the Pt electrode fabricated with electrochemical deposition exhibited the optimal power conversion efficiency. In addition, the DSSC using the Pt electrode fabricated through electrochemical deposition had relatively larger $J_{\mathrm{SC}}$ values but smaller $F F$. This was because the Pt fabricated using electrochemical deposition had the agglomeration of the textured Pt nanostructures, which provided a larger surface area (with large active sites for $\mathrm{I}_{3}{ }^{-}$reduction) and, therefore, a higher $J_{\mathrm{SC}}$. However, the agglomeration of the Pt nanostructures and the lower distribution density of the Pt globular/agglomerated structure on the FTO substrate also led to a larger electrical resistance, resulting in a smaller FF. Comparing our results with the previous literature [24-26], the Pt CEs fabricated in this work exhibited higher efficiencies. In addition, the processes of electrochemical deposition and chemical reduction do not require high-temperature sintering; these two methods are suitable for the fabrication of $\mathrm{Pt}$ on flexible plastic substrates.

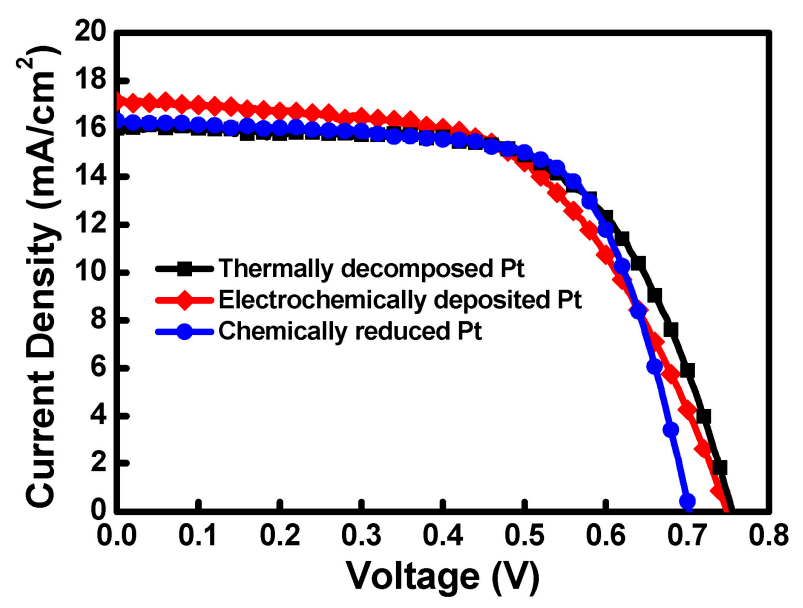

Figure 6. $J-V$ curves of DSSCs based on various Pt CEs.

Table 1. Photovoltaic characteristics of DSSCs based on various Pt counter electrodes.

\begin{tabular}{ccccc}
\hline Counter Electrode & $J_{\text {SC }}\left(\mathbf{m A} / \mathbf{c m}^{2}\right)$ & $V_{\text {OC }}(\mathbf{V})$ & Fill Factor & Eff. (\%) \\
\hline Thermally decomposed Pt & $16.01 \pm 0.05$ & $0.76 \pm 0.01$ & 0.63 & $7.66 \pm 0.13$ \\
Electrochemically deposited Pt & $17.16 \pm 0.06$ & $0.75 \pm 0.01$ & 0.60 & $7.72 \pm 0.14$ \\
Chemically reduced Pt & $16.34 \pm 0.05$ & $0.70 \pm 0.01$ & 0.65 & $7.43 \pm 0.13$ \\
\hline
\end{tabular}

Figure 7 shows the measurement result of the IPCE of the DSSC devices using different Pt counter electrodes. Because all DSSC devices used the N719 dye, light absorption ranged primarily between $300 \mathrm{~nm}$ and $750 \mathrm{~nm}$. In particular, the IPCE peak near $350 \mathrm{~nm}$ was the absorption peak of $\mathrm{TiO}_{2}$, and that near $530 \mathrm{~nm}$ was the absorption peak of the N719 dye. The IPCE peaks for the DSSCs using the Pt electrode fabricated through thermal decomposition, electrochemical deposition, and chemical reduction reaction were $79.3 \%, 88.3 \%$, and $80.2 \%$, respectively. The results showed that the IPCE of the DSSC device using the Pt electrode fabricated through electrochemical deposition was superior to that of the DSSC devices using the Pt fabricated with thermal decomposition or chemical reduction. The result of the IPCE measurement was consistent with that of the $J_{S C}$ values in the $J-V$ analysis. 


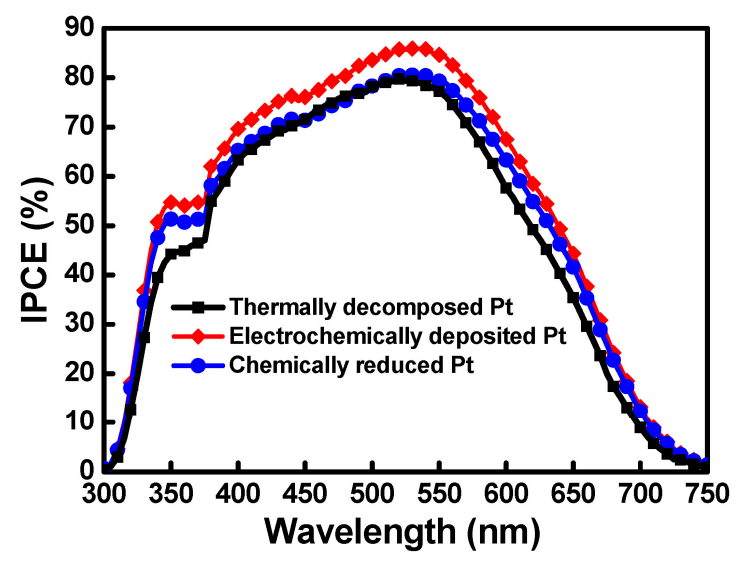

Figure 7. IPCE spectra of DSSCs based on various Pt CEs.

The EIS results of the DSSC devices using different Pt counter electrodes are displayed in Figure 8a. During the impedance measurement, the cell was under constant AM $1.5 \mathrm{G}, 100 \mathrm{~mW} / \mathrm{cm}^{2}$ illumination. The impedance of the DSSC device (cell size: $0.126 \mathrm{~cm}^{2}$ ) was measured by applying a bias at the $V_{\mathrm{OC}}$ of the cell and using an $\mathrm{AC}$ amplitude of $10 \mathrm{mV}$. The frequency range of the impedance spectra was from $0.1 \mathrm{~Hz}$ to $100 \mathrm{kHz}$. The Nyquist plots of the impedance spectra had three semicircles denoting the interface impedance of the counter electrode/electrolyte (frequency was greater than $1 \mathrm{kHz}$ ), the interface impedance of the $\mathrm{TiO}_{2} /$ dye/electrolyte (frequency was between $1 \mathrm{~Hz}$ and $1 \mathrm{kHz}$ ), and the impedance in the electrolyte (frequency was between $0.1 \mathrm{~Hz}$ and $1 \mathrm{~Hz}$ ).

(a)

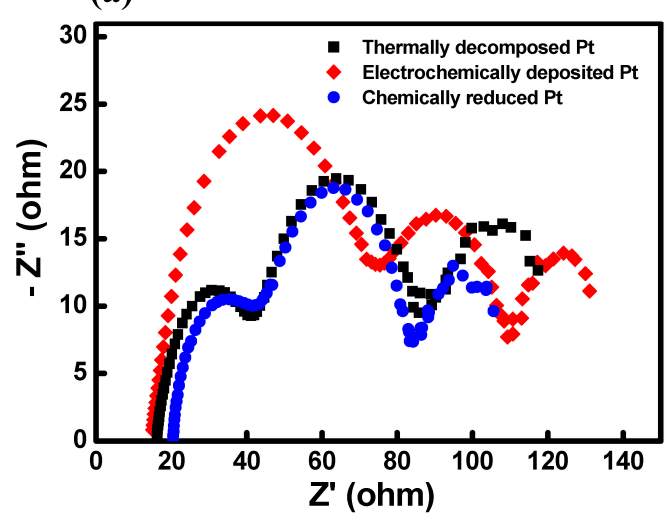

(b)

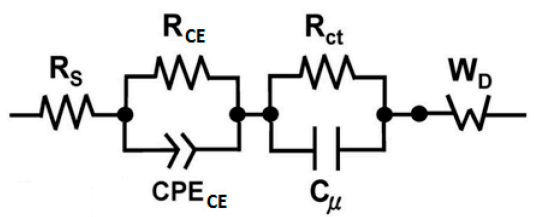

Figure 8. (a) EIS Nyquist plots of DSSCs based on various Pt CEs and (b) the equivalent circuit model used to analyze the internal impedance of the DSSCs.

To extract the quantitative impedance characteristics of the DSSCs, an equivalent circuit model (Figure 8b) was used to analyze the internal impedance of the DSSCs. The electrochemical modeling software ZSimpWin (EChem Software, version 3.2) was used to analyze the EIS data. The extracted quantitative impedance parameters from the EIS Nyquist plots of the devices are listed in Table 2. The series resistance $R_{\mathrm{S}}$ is associated with the contribution from the FTO and counter electrodes. The resistance $R_{\mathrm{CE}}$ is associated with the impedance at the Pt/electrolyte interface. The resistance $R_{\mathrm{ct}}$ is associated with the impedance at the $\mathrm{TiO}_{2} /$ dye/electrolyte interface. $W_{\mathrm{D}}$ (Warburg impedance) corresponds to the ion diffusion resistance of the electrolyte. The left semicircle shows that the impedance of the DSSC using the Pt electrode fabricated through electrochemical deposition was larger than that of the DSSC devices using the Pt fabricated with thermal decomposition and chemical reduction because of the agglomeration of the Pt nanostructures and the lower distribution density of the Pt globular/agglomerated structure on the FTO substrate. On the other hand, at the 
$\mathrm{TiO}_{2} /$ dye/electrolyte interface, the DSSC using the Pt electrode fabricated through electrochemical deposition had the smallest impedance. This implies that the Pt electrode fabricated through electrochemical deposition produced more photogenerated electrons because the agglomeration of $\mathrm{Pt}$ nanostructures also provided a larger surface area. The improvement of $J_{S C}$ is attributed to the high surface area of the Pt electrode fabricated through electrochemical deposition. The role of the Pt CE in DSSCs is to catalyze the reduction of the $\mathrm{I}_{3}{ }^{-}$ions in the electrolyte, which are produced during the regeneration of the oxidized dyes. Therefore, an increase in the surface area of $\mathrm{PtCE}$ can reduce more $\mathrm{I}_{3}{ }^{-}$ions in the electrolyte and regenerate more oxidized dyes, thereby decreasing the recombination resistance at the $\mathrm{TiO}_{2} /$ dye/electrolyte interface.

Table 2. The extract quantitative impedance parameters from the EIS Nyquist plots of the DSSCs.

\begin{tabular}{ccccc}
\hline Counter Electrode & $\boldsymbol{R}_{\mathrm{S}}(\boldsymbol{\Omega})$ & $\boldsymbol{R}_{\mathrm{CE}}(\boldsymbol{\Omega})$ & $\boldsymbol{R}_{\mathrm{ct}}(\boldsymbol{\Omega})$ & $\boldsymbol{W}_{\mathrm{D}}(\boldsymbol{\Omega})$ \\
\hline Thermally decomposed Pt & 16.16 & 27.20 & 41.99 & 40.13 \\
Electrochemically deposited Pt & 15.02 & 59.62 & 35.01 & 28.78 \\
Chemically reduced Pt & 20.24 & 25.82 & 37.08 & 34.64 \\
\hline
\end{tabular}

Figure 9 shows the EIS Bode plots of DSSCs using different Pt CEs. For the frequency range investigated, EIS Bode plots exhibit three peak features: the one at higher frequencies corresponds to the charge transfer at the $\mathrm{Pt} /$ electrolyte interface; the one at middle frequencies corresponds to the charge transfer at the $\mathrm{TiO}_{2} /$ dye/electrolyte interface; and the one at lower frequencies corresponds to the charge transfer in the electrolyte. In the high-frequency region, the DSSCs using the Pt CEs fabricated through electrochemical deposition exhibited a higher intensity of peak and a lower characteristic frequency, indicating a larger charge-transfer resistance at $\mathrm{Pt} / \mathrm{electrolyte}$ interface. Conversely, in the middle frequency region, the DSSCs using the Pt CEs fabricated through electrochemical deposition had the lowest peak intensity, which implies that the Pt CEs fabricated through electrochemical deposition generated the most photoelectrons. The result of the Bode plots was consistent with that of the Nyquist plots.

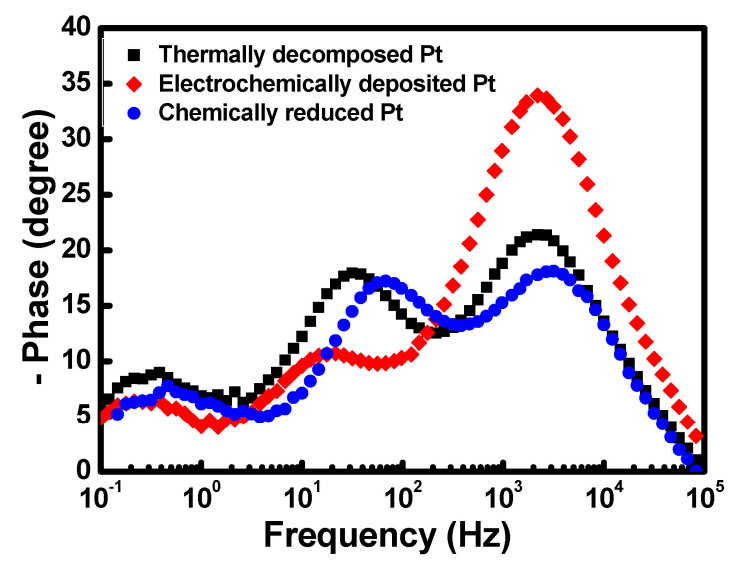

Figure 9. EIS Bode plots of DSSCs based on various Pt CEs.

\section{Conclusions}

In this study, Pt counter electrodes were fabricated using thermal decomposition, electrochemical deposition, and chemical reduction, and the influence of different Pt counter electrodes on the efficiency of the DSSC device was analyzed. According to the result of the SEM analysis, the particle size of the Pt electrode fabricated using thermal decomposition was approximately $60 \mathrm{~nm}$ to $80 \mathrm{~nm}$, and the particles were distributed evenly on the substrate. The phenomenon of particle agglomeration was observed in the Pt electrode fabricated using electrochemical deposition. The globular/agglomerated 
structures ranged between $200 \mathrm{~nm}$ and $800 \mathrm{~nm}$ in size, and textured Pt nanostructures were observed on the surface of the globular/agglomerated structures. The Pt electrode prepared by the chemical reduction reaction method existed as coral-like structures with sizes ranging from approximately $600 \mathrm{~nm}$ to $1200 \mathrm{~nm}$, and the coral-like structures were composed of spherical $\mathrm{Pt}$ with a diameter of $100 \mathrm{~nm}$. Among the three Pt electrodes, the Pt electrode fabricated through electrochemical deposition exhibited the largest surface area. The XRD result revealed that the Pt electrode fabricated using electrochemical deposition featured superior crystallinity, and the CV result showed that the $\mathrm{Pt}$ electrode fabricated through electrochemical deposition exhibited the optimal electrochemical catalytic capability. This study used J-V, IPCE, and EIS measurements to further analyze the characteristics of the DSSC devices using different types of Pt counter electrodes. According to the $J-V$ result, the efficiencies of the three types of DSSCs were between $7.43 \%$ and $7.72 \%$. The DSSCs based on the Pt electrode fabricated through electrochemical deposition exhibited the optimal efficiency. Moreover, a DSSC device fabricated through electrochemical deposition exhibited a relatively higher $J_{S C}$ but smaller $F F$. The reason for this was that the Pt CEs fabricated using electrochemical deposition exhibited the agglomeration of $\mathrm{Pt}$ nanostructures in the electrode and, therefore, exhibited a larger surface area and larger electrical resistance. The EIS results showed that the Pt electrode fabricated through electrochemical deposition produced more photogenerated electrons because the agglomeration of textured Pt nanostructures provided a larger surface area. This study demonstrated that a $\mathrm{Pt} C E$ fabricated using electrochemical deposition and chemical reduction can replace a Pt CE fabricated using thermal decomposition. For electrochemical deposition, the morphology of the Pt electrode can be controlled using the $\mathrm{pH}$ level of the solution, and the thickness of film can be controlled using the voltage and current values. In addition, electrochemical deposition is a common fabrication process in the industry and has great potential because it can be adopted to fabricate large-area electrodes. Because the processes of electrochemical deposition and chemical reduction do not require high-temperature sintering for the fabrication of a Pt electrode, these two methods are suitable for the fabrication of Pt on flexible plastic substrates.

Acknowledgments: The authors gratefully acknowledge the financial support from the Ministry of Science and Technology of Taiwan (MOST 106-2221-E-259-014).

Author Contributions: Chih-Hung Tsai generated ideas, designed experiments, analyzed results, supervised the entire research work, and wrote the manuscript. Yu-Chen Hsiao and Ping-Yuan Chuang performed the experimental work and characterized the materials and devices.

Conflicts of Interest: The authors declare no conflict of interest.

\section{References}

1. O'Regan, B.; Grätzel, M. A low-cost, high-efficiency solar cell based on dye-sensitized colloidal $\mathrm{TiO}_{2}$ films. Nature 1991, 353, 737-740. [CrossRef]

2. Grätzel, M. Photoelectrochemical cells. Nature 2001, 414, 338-344. [CrossRef] [PubMed]

3. Jiu, J.; Isoda, S.; Wang, F.; Adachi, M. Dye-sensitized solar cells based on a single-crystalline $\mathrm{TiO}_{2}$ nanorod film. J. Phys. Chem. B 2006, 110, 2087-2092. [CrossRef] [PubMed]

4. Hagfeldt, A.; Grätzel, M. Molecular photovoltaics. Acc. Chem. Res. 2000, 33, 269-277. [CrossRef] [PubMed]

5. Chiba, Y.; Islam, A.; Watanabe, Y.; Komiya, R.; Koide, N.; Han, L. Dye-sensitized solar cells with conversion efficiency of 11.1\%. Jpn. J. Appl. Phys. 2006, 45, L638. [CrossRef]

6. Chen, C.Y.; Wang, M.; Li, J.Y.; Pootrakulchote, N.; Alibabaei, L.; Ngoc-le, C.; Decoppet, J.; Tsai, J.; Grätzel, C.; $\mathrm{Wu}$, C.G.; et al. Highly efficient light-harvesting ruthenium sensitizer for thin-film dye-sensitized solar cells. ACS Nano 2009, 3, 3103-3109. [CrossRef] [PubMed]

7. Weerasinghe, H.C.; Huang, F.; Cheng, Y.B. Fabrication of flexible dye sensitized solar cells on plastic substrates. Nano Energy 2013, 2, 174-189. [CrossRef]

8. Hou, S.; Lv, Z.; Wu, H.; Cai, X.; Chu, Z.; Yiliguma; Zou, D. Flexible conductive threads for wearable dye-sensitized solar cells. J. Mater. Chem. 2012, 22, 6549-6552. [CrossRef]

9. Li, Q.; Wu, J.; Tang, Q.; Lan, Z.; Li, P.; Lin, J.; Fan, L. Application of microporous polyaniline counter electrode for dye-sensitized solar cells. Electrochem. Commun. 2008, 10, 1299-1302. [CrossRef] 
10. Lin, L.Y.; Tsai, C.H.; Wong, K.T.; Huang, T.W.; Wu, C.C.; Chou, S.H.; Lin, F.; Chen, S.H.; Tsai, A.I. Efficient organic DSSC sensitizers bearing an electron-deficient pyrimidine as an effective $\pi$-spacer. J. Mater. Chem. 2011, 21, 5950-5958. [CrossRef]

11. Qu, S.; Qin, C.; Islam, A.; Wu, Y.; Zhu, W.; Hua, J.; Tian, H.; Han, L. A novel D-A- $\pi$-A organic sensitizer containing a diketopyrrolopyrrole unit with a branched alkyl chain for highly efficient and stable dye-sensitized solar cells. Chem. Commun. 2012, 48, 6972-6974. [CrossRef] [PubMed]

12. Yun, S.; Hagfeldt, A.; Ma, T. Pt-free counter electrode for dye-sensitized solar cells with high efficiency. Adv. Mater. 2014, 26, 6210-6237. [CrossRef] [PubMed]

13. Hauch, A.; Georg, A. Diffusion in the electrolyte and charge-transfer reaction at the platinum electrode in dye-sensitized solar cells. Electrochim. Acta 2001, 46, 3457-3466. [CrossRef]

14. Wang, M.; Lin, Y.; Zhou, X.; Xiao, X.; Yang, L.; Feng, S.; Li, X. Solidification of liquid electrolyte with imidazole polymers for quasi-solid-state dye-sensitized solar cells. Mater. Chem. Phys. 2008, 107, 61-66. [CrossRef]

15. Papageorgiou, N.; Maier, W.F.; Grätzel, M. An iodine/triodide reduction electrocatalyst for aqueous and organic media. J. Electrochem. Soc. 1997, 144, 876-884. [CrossRef]

16. Fang, X.; Ma, T.; Guan, G.; Akiyama, M.; Kida, T.; Abe, E. Effect of the thickness of the Pt film coated on a counter electrode on the performance of a dye-sensitized solar cell. J. Electroanal. Chem. 2004, 570, 257-263. [CrossRef]

17. Suzuki, K.; Yamaguchi, M.; Kumagai, M.; Yanagida, S. Application of carbon nanotubes to counter electrodes of dye-sensitized solar cells. Chem. Lett. 2003, 32, 28-29. [CrossRef]

18. Huang, Z.; Liu, X.; Li, K.; Li, D.; Luo, Y.; Li, H.; Song, W.; Chen, L.; Meng, Q. Application of carbon materials as counter electrodes of dye-sensitized solar cells. Electrochem. Commun. 2007, 9, 596-598. [CrossRef]

19. Saito, Y.; Kitamura, T.; Wada, Y.; Yanagida, S. Application of poly(3,4-ethylenedioxythiophene) to counter electrode in dye-sensitized solar cells. Chem. Lett. 2002, 31, 1060-1061. [CrossRef]

20. Saito, Y.; Kubo, W.; Kitamura, T.; Wada, Y.; Yanagida, S. $\mathrm{I}^{-} / \mathrm{I}_{3}{ }^{-}$redox reaction behavior on poly $(3,4-$ ethylenedioxythiophene) counter electrode in dye-sensitized solar cells. J. Photochem. Photobiol. A 2004, 164, 153-157. [CrossRef]

21. Jiang, Q.W.; Li, G.R.; Xiao, X.P. Highly ordered TiN nanotube arrays as counter electrodes for dye-sensitized solar cells. Chem. Commun. 2009, 41, 6720-6722. [CrossRef] [PubMed]

22. Wang, M.K.; Anghel, A.M.; Marsan, B.; Ha, N.-L.C.; Pootrakulchote, N.; Zakeeruddin, S.M.; Grätzel, M. CoS supersedes $\mathrm{Pt}$ as efficient electrocatalyst for triiodide reduction in dye-sensitized solar cells. J. Am. Chem. Soc. 2009, 131, 15976-15977. [CrossRef] [PubMed]

23. Murakami, T.N.; Grätzel, M. Counter electrodes for DSC: Application of functional materials as catalysts. Inorg. Chim. Acta 2008, 361, 572-580. [CrossRef]

24. Fang, X.; Ma, T.; Guan, G.; Akiyama, M.; Abe, E. Performances characteristics of dye-sensitized solar cells based on counter electrodes with Pt films of different thickness. J. Photochem. Photobiol. A 2004, 164, 179-182. [CrossRef]

25. Li, P.; Wu, J.; Lin, J.; Huang, M. Improvement of performance of dye-sensitized solar cells based on electrodeposited-platinum counter electrode. Electrochim. Acta 2008, 53, 4161-4166. [CrossRef]

26. Yoon, C.H.; Vittal, R.; Lee, J.; Chae, W.S.; Kim, K.J. Enhanced performance of a dye-sensitized solar cell with an electrodeposited-platinum counter electrode. Electrochim. Acta 2008, 53, 2890-2896. [CrossRef]

27. Koo, B.K.; Lee, D.Y.; Kim, H.J.; Lee, W.J.; Song, J.S.; Kim, H.J. Seasoning effect of dye-sensitized solar cells with different counter electrodes. J. Electroceram. 2006, 17, 79-82. [CrossRef]

28. Bay, L.; West, K.; Winther-Jensen, B.; Jacobsen, T. Electrochemical reaction rates in a dye-sensitised solar cell-the iodide/tri-iodide redox system. Sol. Energy Mater. Sol. Cells 2006, 90, 341-351. [CrossRef]

29. Kim, S.S.; Nah, Y.C.; Noh, Y.Y.; Jo, J.; Kim, D.Y. Electrodeposited Pt for cost-efficient and flexible dye-sensitized solar cells. Electrochim. Acta 2006, 51, 3814-3819. [CrossRef]

30. Wei, T.C.; Wan, C.C.; Wang, Y.Y. Poly(N-vinyl-2-pyrrolidone)-capped platinum nanoclusters on indium-tin oxide glass as counterelectrode for dye-sensitized solar cells. Appl. Phys. Lett. 2006, 88, 103122. [CrossRef]

31. Tsai, C.H.; Fei, P.H.; Chen, C.H. Investigation of Coral-Like $\mathrm{Cu}_{2} \mathrm{O}$ Nano/Microstructures as Counter Electrodes for Dye-Sensitized Solar Cells. Materials 2015, 8, 5715-5729. [CrossRef] [PubMed]

(C) 2018 by the authors. Licensee MDPI, Basel, Switzerland. This article is an open access article distributed under the terms and conditions of the Creative Commons Attribution (CC BY) license (http:/ / creativecommons.org/licenses/by/4.0/). 